\title{
Ramesh P. Singh and Darius Bartlett (Eds): Natural Hazards: Earthquakes, Volcanoes and Landslides
}

Ken Jones ${ }^{1}$

(c) Springer-Verlag GmbH Germany, part of Springer Nature 2018 erosion are wind and water, whilst the more minor glacial erosion, caves, springs and biological causes are also considered. A separate chapter on dust storms stresses the major impact such storms exert on the atmosphere, exemplified by the Saharan sand found so regularly throughout Europe. Apart from the removal of large quantities of nutrient-rich fertile topsoil, minute soil particles are carried into the atmosphere, causing multiple health problems to desert dwellers and many others, even spreading over places that exist very large distances from the source of the dust. Arid and semi-arid regions cover some $41 \%$ of the worlds land area. Wind erosion is a very major problem that cannot be questioned, but much of the cause is thought to be overgrazing by the local populace - but this is a political issue, not one of science.

Two forms of subsidence are dealt with; coastal and those occurring on the earth's surface, the latter divided into shallow and deep, caused by mining activity and tectonic shift. Prediction of events still largely relies upon point-to-point observation, using the geodetic techniques of InSAAR and PSinSAAR. Earthquakes, amongst the most devastating of natural hazards, are most abundant along the boundaries of lithospheric plates. This fact suggests a better knowledge of the science should allow a higher degree of predictability. However, with plate boundaries running for thousands of kilometres, and stress areas hundreds of kilometres wide, no methods of more precise prediction are suggested.

The most spectacular events are erupting volcanoes. Unlike the other natural hazards, these are always located in a fixed area, creating the advantage of relatively low observation costs, timeliness and continuity. Although the book's introduction implied a link with climate change, this theme is not developed in any convincing way by any of the authors. It is very clear that despite the application of a whole battery of well-established scientific instrumentation, coupled with satellite observations, prediction of future natural hazard events remains elusive.

Ken Jones

chromatographia@springer.com

1 Knutsford, UK 